\title{
Involvement of P-glycoprotein and Multidrug Resistance Associated Protein 1 on the Transepithelial Transport of a Mercaptoacetamide-Based Histone-Deacetylase Inhibitor in Caco-2 Cells
}

\author{
Zacharoula Konsoula and Mira JunG* \\ Department of Radiation Medicine, Lombardi Cancer Center, Georgetown University Medical Center; Washington, D.C. \\ 20057-1482, U.S.A. Received August 20, 2008; accepted September 29, 2008; published online October 7, 2008
}

Oral bioavailability is one of the important criteria for development of a drug-lead candidate. In this study, the absorptive characteristics and the efflux mechanism of a mercaptoacetamide-based histone deacetyalse (HDAC) inhibitor, coded as W2, were investigated using Caco-2 cells. The transport of W2 was asymmetric as indicated by 1.85 fold higher basolateral to apical (BL to AP) than apical to basolateral (AP to BL) flux. Such asymmetry was associated with multidrug resistance associated protein 1 (MRP1) and P-glycoprotein (P-gp), as evidenced by specific inhibition of these proteins. In the presence of verapamil and cyclosporin $A$, potent inhibitors of P-gp, the apparent permeability ratio $\left(P_{\text {app }}\right.$ BL to AP/P $P_{\text {app }}$ AP to BL) of W2 was decreased from 1.85 to 0.73 and 1.03 , respectively, and the absorption from apical to basolateral side was enhanced from $13.3 \pm 0.2 \times 10^{-6} \mathrm{~cm} / \mathrm{s}$ to $17.3 \pm 0.12 \times 10^{-6} \mathrm{~cm} / \mathrm{s}$ and $19 \pm 0.3 \times 10^{-6} \mathrm{~cm} / \mathrm{s}$, respectively. Upon addition of quinidine, a mixed P-gp and MRP1 inhibitor, the permeation of W2 from the apical side was significantly increased $\left(P_{\text {app }}\right.$ $\left.17.1 \pm 0.32 \times 10^{-6} \mathrm{~cm} / \mathrm{s}\right)$ while the efflux was inhibited $\left(P_{\text {app }} 21.3 \pm 0.19 \times 10^{-6} \mathrm{~cm} / \mathrm{s}\right)$. Furthermore, the influence of the MRP1 inhibitors, indomethacin and $N$-benzyl-indomethacin (NBI) was evaluated. NBI treatment attenuated the basolateral to apical flux of W2 $\left(P_{\text {app }} 20.3 \pm 0.1 \times 10^{-6} \mathrm{~cm} / \mathrm{s}\right)$, whereas this effect was completely abrogated by indomethacin $\left(P_{\text {app }} 11 \pm 0.4 \times 10^{-6} \mathrm{~cm} / \mathrm{s}\right)$. The results suggest that P-gp and MRP1 transporters are capable of mediating the efflux of $\mathrm{W} 2$ and might play a significant role in its oral absorption. cell line

Key words histone deacetylase inhibitor; mercaptoacetamide; P-glycoprotein; multidrug resistance associated protein 1; caco-2

It is well documented that histone acetyltransferases (HATs) and histone deacetylases (HDACs) are important regulators of chromatin and play central role as transcriptional modifiers. ${ }^{1)}$ Abnormal HAT or HDAC activity has been reported in several cancers. ${ }^{2)}$ Inhibition of HDACs often results in cellular differentiation, growth arrest and apoptosis in a broad spectrum of tumor cells and in vivo. ${ }^{3)}$ Several HDAC inhibitors such as vorinostat (suberoylanilide hydroxamic acid), ${ }^{4)}$ MS-275, ${ }^{5)}$ phenylbutyrate $^{6)}$ and depsipeptide ${ }^{7)}$ have shown potent anti-tumor activities and are currently in Phase I and II clinical trials. Recently, vorinostat was approved for the treatment of cutaneous T-cell lymphoma (CTCL).

One of the most important reasons for chemotherapy resistance is the increased expression of the ATP-binding cassette $(\mathrm{ABC})$ transport proteins which lower intracellular anticancer drug concentrations in an energy-dependent manner. The ABC family includes among others the multidrug resistance associated proteins (MRP), P-glycoprotein (P-gp) and breast cancer resistance protein (BCRP). In the intestinal epithelium several ABC transporters are localized in the apical membrane of the enterocyte, including P-gp, MRP2 and BCRP, catalyzing the efflux of compounds to the intestinal luminal side. ${ }^{8)}$ The MRP1, MRP3 and MRP5 transport proteins are located on the basolateral membrane of the enterocyte, thus catalyzing the efflux of compounds to the serosal side. ${ }^{9)}$

The human colonic adenocarcinoma Caco- 2 cell line is the most widely employed in vitro model that mimics the absorptive properties of the intestinal epithelium. ${ }^{10)}$ The Caco-2 cell model has been used for evaluating the intestinal transport mechanism of metals, nutrients and drugs. ${ }^{11,12)}$ These cells spontaneously differentiate in culture into polarized mono- layers and exhibit morphological features such as tight junctions, microvilli, and brush border enzymes found in enterocytes. ${ }^{13,14)}$ Additionally, due to the fact that drug efflux proteins are functionally expressed in Caco- 2 membranes, ${ }^{15)}$ these cells have been employed extensively for studying P-gp or MRP mediated transport. ${ }^{16,17)}$

6-[(2-Mercaptoacetyl)amino- $N$-8-quinolinyl-hexamide $]$ (6MAQH) coded as W2 (Fig. 1) is a mercaptoacetamidebased HDAC inhibitor with potent anti-tumor activities in a broad spectrum of solid and hematologic malignancies. ${ }^{18)}$ Previous studies conducted in our laboratory have shown that the secretary permeation (basolateral to apical) of W2 was higher than the absorptive (apical to basolateral). ${ }^{19)}$ The asymmetry observed between absorption and secretion fluxes can be attributed to an active transporter, effluxing W2 towards the apical compartment. Such transporters have already been described, as they are related to the resistance of various tissues to xenobiotics. ${ }^{20)}$ Hence, it was of interest to explore both P-gp and MRP inhibition in this study in order to elucidate the W2 transport through tight cell monolayers. We hypothesized that inhibition of intestinal P-gp might decrease the efflux of $\mathrm{W} 2$ from the blood into the intestinal lumen, thereby, increasing the bioavailability of the compound. The P-gp inhibitors (verapamil, cyclosporin A), ${ }^{21,22)}$ the mixed inhibitor of P-gp/MRP1 (quinidine) as well as the MRP1 inhibitors (indomethacin, $N$-benzyl-indometha$(\operatorname{cin})^{23,24)}$ have been selected in order to distinguish the possi-

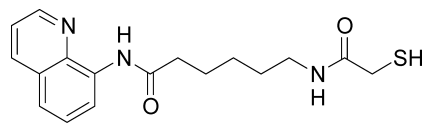

Fig. 1. Chemical Structure of 6-[(2-Mercaptoacetyl)amino- $N$-8-quinolinyl-hexamide] (6MAQH) Coded as W2 
ble carriers implicated in the transport of W2.

\section{MATERIALS AND METHODS}

Materials Caco- 2 cells were obtained from the Tissue Culture Shared Resources of the Lombardi Comprehensive Cancer Center. Dulbecco's Modified Eagle Medium (DMEM) containing D-glucose $(4.5 \mathrm{~g} / \mathrm{l})$ and L-glutamine, Hanks' balanced salt solution (HBSS), $0.05 \%$ trypsin-EDTA, phosphate buffered saline (PBS, $\mathrm{pH} 7.4)$, penicillin-streptomycin $(10000 \mathrm{U} / \mathrm{ml}-10000 \mu \mathrm{g} / \mathrm{ml})$, non-essential amino acids (NEAA), fetal bovine serum were purchased from Invitrogen (Carlsbad, CA, U.S.A.). Transwell ${ }^{\circledR}$ inserts (12-well plates, $12 \mathrm{~mm}$ diameter, $1.12 \mathrm{~cm}^{2}$ surface area) with permeable polycarbonate membranes $(3.0 \mu \mathrm{m}$ pore size $)$ were purchased from Costar (Cambridge, MA, U.S.A.). Verapamil hydrochloride, cyclosporin A, quinidine hydrochloride monohydrate, indomethacin, $N$-benzyl-indomethacin (NBI), acetonitrile (LC-MS Chromsolv ${ }^{\circledR}$ for HPLC), lucifer yellow $\mathrm{CH}$ dipotassium salt were supplied by Sigma-Aldrich (St. Louis, MO, U.S.A.).

Cell Culture Caco-2 cells were grown in DMEM supplemented with $10 \%$ fetal bovine serum, 1\% (NEAA), $1 \%$ glutamine, $5 \%$ penicillin and streptomycin in a humidified atmosphere of $5 \% \mathrm{CO}_{2}$ and $95 \%$ air at $37^{\circ} \mathrm{C}$. Caco- 2 cells were used between passages 30-40. For transport experiments, $5 \times 10^{5}$ cells were seeded on polycarbonate inserts and cultured as previously described by Konsoula and Barile. ${ }^{25}$ ) Briefly, cells were allowed to grow and differentiate on inserts for $21-28 \mathrm{~d}$. The medium was changed three times a week. The cell monolayer integrity was evaluated by measuring the transepithelial electrical resistance (TEER) with a Millicell-ERS Voltohmmeter (Millipore Corp., Bedford, MA, U.S.A.). TEER values greater than $400 \Omega \mathrm{cm}^{2}$ were used for the transport studies. The TEER values of the Caco- 2 cell monolayer were assessed before and after the transport experiments. In addition, the flux of lucifer yellow was used as a negative control to evaluate the integrity of the monolayer.

Transport Kinetic Studies The transport studies were performed as previously described by Konsoula and Jung. ${ }^{19}$ Briefly, the Caco-2 cell monolayers were washed twice with phosphate buffered saline (PBS) and pre-incubated for 15 min in Hanks' balanced salt solution (HBSS) buffer $(\mathrm{pH}$ $7.4)$ at $37^{\circ} \mathrm{C}$ in a shaking water bath $(100 \mathrm{rpm})$. Transepithelial transport was assayed by placing $150 \mathrm{nmol} / \mathrm{ml}$ of W2 either in the apical (insert) or basolateral (well) sides of Caco-2 cells. The volumes on the apical and basolateral compartments were maintained at 0.5 and $1.5 \mathrm{ml} \mathrm{HBSS} \mathrm{(pH} \mathrm{7.4),} \mathrm{re-}$ spectively. At the indicated time intervals $(0,15,30,60,90$, $120 \mathrm{~min}$ ), $100 \mu \mathrm{l}$ were withdrawn from each receiver compartment and replaced with equal volumes of HBSS buffer. The dilution was taken into consideration for the transport calculations. Appearance of $\mathrm{W} 2$ in the receiver side was presented as the fraction of total compound added at the beginning of the experiment. The samples were analyzed by high performance liquid chromatography (HPLC). The data points represent the mean of three independent determinations.

Transport Inhibition Studies The inhibition of efflux of W2 across Caco-2 cells was investigated in the presence of two common P-gp inhibitors verapamil $(50,100 \mu \mathrm{M})$ and cyclosporin A $(4 \mu \mathrm{M})$, the MRP1 inhibitors indomethacin
$(140 \mu \mathrm{M})$ and $N$-benzyl-indomethacin (NBI) $(145 \mu \mathrm{M})$ as well as the mixed P-gp/MRP1 inhibitor quinidine $(264 \mu \mathrm{M})$. The concentrations of the inhibitors were based on literature information. In addition, concentration inhibition response experiments were conducted for W2 transport in the presence of the inhibitors. The inhibitors were applied in both apical and basolateral compartments, $15 \mathrm{~min}$ prior to conducting the studies. During the course of the experiment, the inhibitors were present in the donor chamber with W2 as well as in the receiver chamber at the same concentrations as stated above. These experiments were conducted according to the same protocol as the transport kinetic studies. At the end of the transport experiments, the monolayer integrity was evaluated by measuring the TEER and the flux of lucifer yellow.

Apparent Permeability Coefficients $\left(\boldsymbol{P}_{\text {app }}\right)$ The apparent permeability coefficient values of W2 $\left(P_{\text {app }} \mathrm{cm} / \mathrm{s}\right)$ were evaluated from the linear part of the plot of the total amount of W2 transported by Caco- 2 cell monolayers vs. time, employing the following equation ${ }^{26,27)}$

$$
P_{\text {app }}=\frac{V_{\mathrm{r}}}{A \times C_{\mathrm{o}}} \times \frac{d C}{d t}
$$

where $d C / d t(\mathrm{nmol} / \mathrm{ml} \mathrm{s})$ is the rate at which W2 appears in the receiver side, calculated using linear regression analysis (Microsoft Excel function), $V_{\mathrm{r}}$ is the volume in the receiver chamber $(\mathrm{ml}), A$ is the membrane surface area $\left(\mathrm{cm}^{2}\right)$ and $C_{\mathrm{o}}$ is the initial concentration of $\mathrm{W} 2$ in the donor chamber ( $\mathrm{nmol} / \mathrm{ml})$.

Efflux Ratios (ER) Efflux ratios (ER) of W2 in the absence or presence of the inhibitors were determined from the apparent permeability coefficient values using the following equation:

$$
\mathrm{ER}=P_{\text {app }} \mathrm{BL} \text { to } \mathrm{AP} / P_{\text {app }} \mathrm{AP} \text { to } \mathrm{BL}
$$

where $P_{\text {app }} \mathrm{BL}$ to $\mathrm{AP}$ and $P_{\text {app }}$ AP to $\mathrm{BL}$ ratio displays the permeability values in the secretory and absorptive directions, respectively.

Chromatographic Conditions The amount of W2 was quantified using the HPLC method as previously described by Konsoula and Jung. ${ }^{19)}$ Briefly, LC was performed using a Shimadzu LC-20AD HPLC system consisting of a UV/VIS detector (SDP-20AV), degasser (DGU-20A), and an autosampler $\left(\mathrm{SIL}_{\mathrm{H}} \mathrm{HT}_{\mathrm{A}}\right)$. LC was carried out on an analytical column (Phenomenex Luna C18 (2); $3.0 \mu \mathrm{m}, 100$ by $4.6 \mathrm{~mm})$. The mobile phase consisted of acetonitrile-water with $0.1 \%$ acetic acid $(50: 50, \mathrm{v} / \mathrm{v})$. The injection volume was $20 \mu \mathrm{l}$ and the flow rate was $1 \mathrm{ml} / \mathrm{min}$. The wavelength for detection of W2 was $330 \mathrm{~nm}$.

Statistical Analysis All experiments were performed at least in triplicate. Results are presented as mean values \pm S.D. Statistical analysis was calculated using the Student's twotailed unpaired $t$-test or one-way analysis of variance (oneway ANOVA). A value of $p<0.05$ was considered significant.

\section{RESULTS}

P-gp is a transporter which is located on the apical side of the intestinal epithelium and is responsible for the efflux of a variety of xenobiotics from the cytosol into the lumen, leading to a limited absorption and enhanced elimination of such 


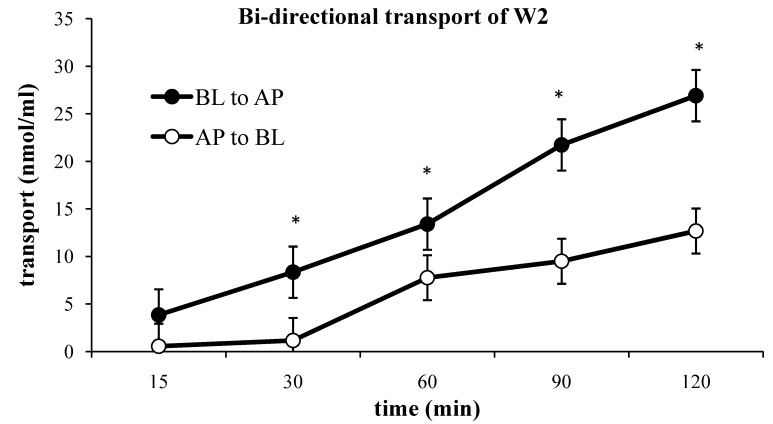

Fig. 2. Basolateral to Apical (BL to AP) and Apical to Basolateral (AP to BL) Transport of W2 across Caco-2 Cell Monolayers

$*$ Denotes significant differences between the transport directions, $p<0.05$. The data points represent the mean values \pm S.D. of three independent determinations.

BL to AP transport of W2

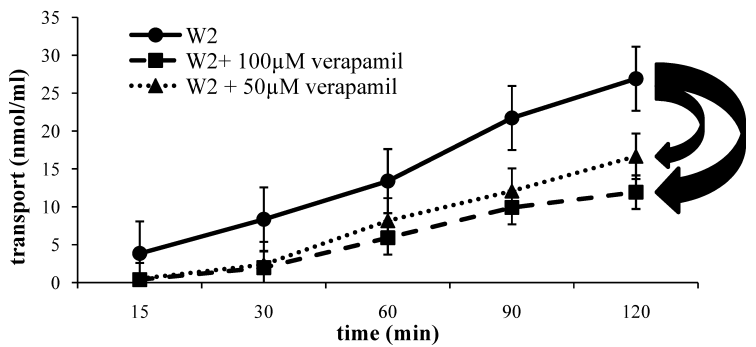

Fig. 3. Effect of Verapamil on the Basolateral to Apical Transport of W2

Verapamil $(50 \mu \mathrm{M}$ or $100 \mu \mathrm{M})$ was applied in both apical and basolateral compartments of Caco-2 cells, 15 min before the beginning of the experiment. Each point represents the mean \pm S.D. of three experiments.

compounds. $^{28,29)}$ A distinctive feature of P-gp substrates is that they demonstrate a higher transport in the excretive direction (BL to $\mathrm{AP}$ ) compared to that in the opposite direction (AP to BL). Polarized Caco-2 cells have been described to express P-gp abundantly at the apical side. ${ }^{30)}$ The results indicate that the transport of W2 across Caco-2 brush-border membranes took place in both apical to basolateral (AP to $\mathrm{BL}$ ) and basolateral to apical (BL to AP) directions; however, the transport of $\mathrm{W} 2$ was asymmetric, favoring permeation in the basolateral to apical direction (Fig. 2). The $P_{\text {app }}$ ratio $\left(P_{\text {app }}\right.$ $\mathrm{BL}$ to $\mathrm{AP} / P_{\text {app }} \mathrm{AP}$ to $\mathrm{BL}$ ) was 1.85 , which suggests the involvement of an efflux transporter for W2 (Table 1). It has to be noted that a $24 \mathrm{~h}$ exposure of Caco- 2 cell monolayers to $\mathrm{W} 2$ at a concentration of $150 \mathrm{nmol} / \mathrm{ml}$ had no significant effect on cell viability as determined by MTT assay (data not shown).

To investigate whether P-gp was implicated in W2 intestinal uptake, we evaluated the effect of verapamil, a well established P-gp inhibitor. ${ }^{21,31)}$ The addition of the inhibitors described below had neither a significant decrease in TEER nor a significant increase in lucifer yellow flux through the Caco-2 cell monolayers (data not shown). As illustrated in Fig. 3, verapamil inhibited the BL to AP efflux of W2 in a concentration-dependent manner. Verapamil at 50 and $100 \mu \mathrm{m}$ significantly decreased the BL to AP efflux of W2 by $30 \%$ and $48.5 \%(p<0.05)$ respectively. Moreover, verapamil $(100 \mu \mathrm{M})$ caused a 1.3 fold increase in the AP to BL flux of $\mathrm{W} 2$. The efflux ratio (ER) of $\mathrm{W} 2$ was determined to be equal to 1.28 and 0.73 in the presence of 50 and $100 \mu \mathrm{M}$ verapamil respectively (Table 1), indicating that the efflux of the com-
Table 1. Comparison of the Absorptive and Secretory Coefficients $\left(P_{\mathrm{app}}\right)$ and the Efflux Ratios of W2 in the Absence or Presence of Inhibitors across Polarized Caco-2 Cell Monolayers

\begin{tabular}{lccc}
\hline \multirow{2}{*}{ W2 \pm inhibitors } & \multicolumn{2}{c}{$P_{\text {app }}\left(\times 10^{-6} \mathrm{~cm} / \mathrm{s}\right)$} & $\begin{array}{c}P_{\text {app }} \text { BL to AP/ } \\
P_{\text {app }} \text { AP to BL }\end{array}$ \\
\cline { 2 - 4 } & BL to AP & AP to BL & \\
\hline W2 & $24.7 \pm 0.12$ & $13.3 \pm 0.2$ & 1.85 \\
W2 \pm verapamil $(50 \mu \mathrm{M})$ & $17.2 \pm 0.32^{\mathrm{c}}$ & $13.4 \pm 0.15$ & 1.28 \\
W2 \pm verapamil $(100 \mu \mathrm{M})$ & $12.7 \pm 0.22^{\mathrm{c}}$ & $17.3 \pm 0.12^{\mathrm{d}}$ & 0.73 \\
$\mathrm{~W} 2 \pm$ cyclosporin A $(4 \mu \mathrm{M})$ & $19.7 \pm 0.2^{\mathrm{c}}$ & $19 \pm 0.3^{\mathrm{d}}$ & 1.03 \\
$\mathrm{~W} 2 \pm$ quinidine $(264 \mu \mathrm{M})$ & $21.3 \pm 0.19^{\mathrm{c}}$ & $17.1 \pm 0.32^{\mathrm{d}}$ & 1.24 \\
$\mathrm{~W} 2 \pm$ indomethacin $(140 \mu \mathrm{M})$ & $11 \pm 0.4^{\mathrm{c}}$ & $14.3 \pm 0.18$ & 0.77 \\
$\mathrm{~W} 2 \pm N$-benzyl indomethacin & & & \\
$(\mathrm{NBI})(145 \mu \mathrm{M})$ & $20.3 \pm 0.1^{\mathrm{c}}$ & $21.7 \pm 0.11^{\mathrm{d}}$ & 0.93 \\
\hline
\end{tabular}

Inhibitors were applied in both apical and basolateral compartments. Net efflux of W2 was calculated as the ratio of basolateral to apical permeability $P_{\text {app }}$ to apical to basolateral permeability $P_{\text {app. }}$. Data are presented as the mean \pm S.D. $(n=3)$. Significant differences from the $P_{\text {ap }}$ values of W2 in the absence of inhibitor in a given direction $(\mathrm{c}, \mathrm{d})$ are shown, $p<0.05$.

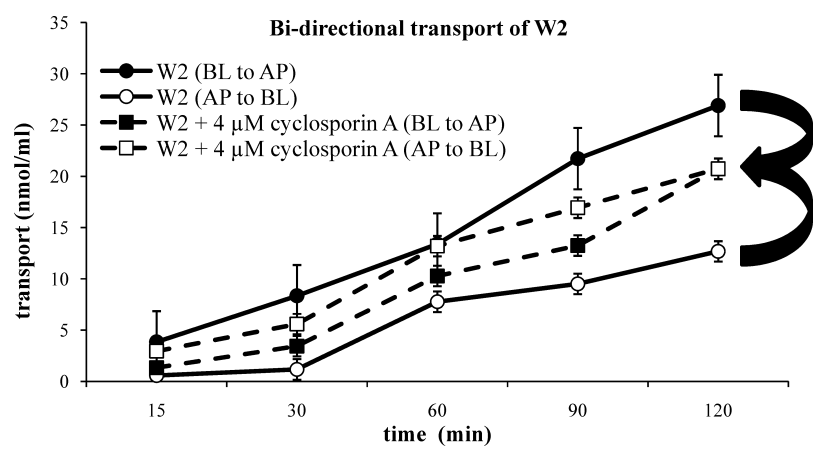

Fig. 4. Effect of Cyclosporin A on the Bi-directional Transport of W2

Cyclosporin A $(4 \mu \mathrm{M})$ was applied in both apical and basolateral compartments of Caco- 2 cells, 15 min before the beginning of the experiment. Each point represents the mean \pm S.D. of three independent experiments.

pound is P-gp mediated. The amount of W2 in the apical and basolateral sides was determined at the end of the transport inhibition studies. More than $90 \%$ of W2 initially used for cell exposure was recovered, suggesting that W2 was not significantly degraded or metabolized in Caco- 2 cells.

To confirm the implication of P-gp in the W2 transport on the Caco-2 cell model, $4 \mu \mathrm{M}$ cyclosporin $\mathrm{A}^{32)}$ was added to both sides of the monolayer. Cyclosporin A essentially abolished the polarized transport of W2; the $P_{\text {app }}$ values of W2 significantly lowered $(p<0.05)$ in the excretory direction $\left(P_{\text {app }}\right.$ BL to $\left.\mathrm{AP}=19.7 \pm 0.2 \times 10^{-6} \mathrm{~cm} / \mathrm{s}\right)$ and enhanced in the absorptive direction $\left(P_{\text {app }}\right.$ AP to $\left.\mathrm{BL}=19 \pm 0.3 \times 10^{-6} \mathrm{~cm} / \mathrm{s}\right)$ (Fig. 4). The difference in the transport rate of $\mathrm{W} 2$ in the absence and presence of cyclosporin A suggests the involvement of P-gp.

The bi-directional transport of W2 across Caco- 2 cell monolayer was examined in the presence of quinidine $(264 \mu \mathrm{M})$, a mixed inhibitor of P-gp/MRP1 ${ }^{33)}$ (Fig. 5). Absorptive and secretory routes of $\mathrm{W} 2$ were compared using apparent permeability $\left(P_{\text {app }}\right)$ values. According to the results, when quinidine was applied to the both sides of the monolayer, the cellular uptake of W2 from the apical side was significantly increased $\left(P_{\mathrm{app}}\right.$ AP to BL $\left.17.1 \pm 0.32 \times 10^{-6} \mathrm{~cm} / \mathrm{s}\right)$ $(p<0.05)$ while the efflux was inhibited $\left(P_{\mathrm{app}} \mathrm{BL}\right.$ to $\mathrm{AP}$ $\left.21.3 \pm 0.19 \times 10^{-6} \mathrm{~cm} / \mathrm{s}\right)$. Therefore, both W2 transports (Table 1) were sensitive to the presence of the mixed P-gp 


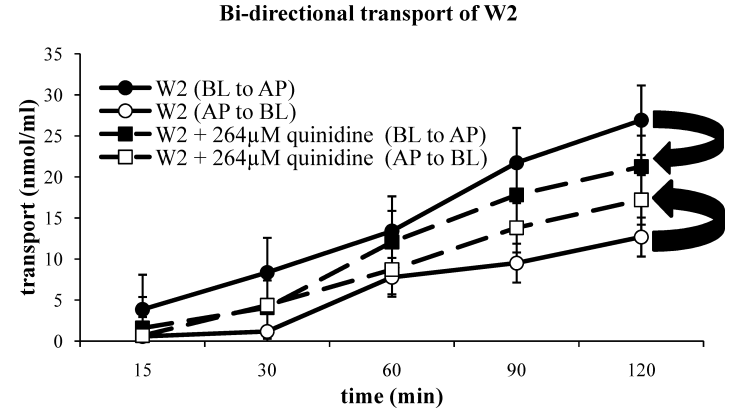

Fig. 5. Effect of Quinidine on the Bi-directional Transport of W2

Quinidine $(264 \mu \mathrm{M})$ was applied in both apical and basolateral compartments of Caco-2 cells, 15 min before the beginning of the experiment. Each point represents the mean \pm S.D. of three experiments.

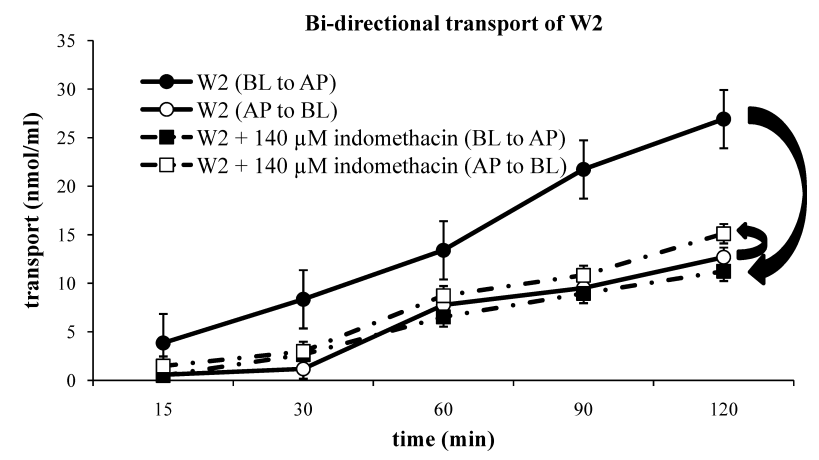

Fig. 6. Effect of Indomethacin on the Bi-directional Transport of W2

Indomethacin $(140 \mu \mathrm{M})$ was applied in both apical and basolateral compartments of Caco-2 cells, 15 min before the beginning of the experiment. Each point represents the mean \pm S.D. of three experiments.

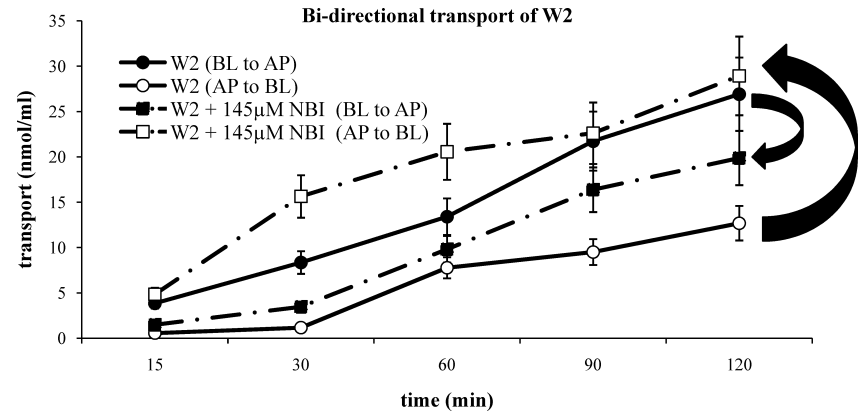

Fig. 7. Effect of $N$-Benzyl-indomethacin (NBI) on the Bi-directional Transport of W2

NBI $(145 \mu \mathrm{M})$ was applied in both apical and basolateral compartments of Caco-2 cells, $15 \mathrm{~min}$ before the beginning of the experiment. Each point represents the mean \pm S.D. of three experiments.

and MRP1 inhibitor.

Relating to the data above, we hypothesized that an additional energy carrier is involved in the W2 transport. The expression of MRP proteins on the Caco- 2 cells, provides a model to study MRP-mediated transport. To explore that mechanism of transport of W2, we performed inhibitory studies with the MRP1 inhibitors ${ }^{23,24)}$ indomethacin and $N$ benzyl-indomethacin (NBI) (Figs. 6, 7). NBI treatment attenuated the basolateral to apical flux of W2 by $17.8 \%$ in Caco2 cells, whereas this effect was completely abrogated by the presence of indomethacin $(55.4 \%$ reduction $)(p<0.05)$. Similarly, NBI significantly enhanced $(p<0.05)$ the influx permeability of W2 $\left(P_{\text {app }}\right.$ AP to BL $\left.21.7 \pm 0.11 \times 10^{-6} \mathrm{~cm} / \mathrm{s}\right)$ whereas indomethacin resulted in a moderate increase $\left(P_{\text {app }}\right.$ AP to BL $\left.14.3 \pm 0.18 \times 10^{-6} \mathrm{~cm} / \mathrm{s}\right)(p>0.05)($ Table 1$)$. These findings suggest that MRP might play a role in limiting the oral absorption of W2.

\section{DISCUSSION}

Histone deacetylase inhibitors (HDACIs) are emerging as a new class of therapeutic agents with potent antitumor activities in a broad spectrum of human cancers. The mercaptoacetamide end moiety of HDACIs has been shown to be a good replacement of the hydroxamic acid; since zinc ion is highly thiophilic, thiol derivatives might inhibit HDAC activity by forming a covalent disulfide bond with the cysteine residues of the zinc dependent enzyme. ${ }^{34)}$ Previously, we have demonstrated that the mercaptoacetamide-based HDAC inhibitor (W2) is associated with good physicochemical properties, favorable pharmacokinetics and long in vitro plasma half lives. ${ }^{19)}$

Oral anticancer chemotherapy is becoming an accepted and standard treatment of cancer, due to several advantages including convenience, reduced financial cost, and prolonged exposure to cytotoxic agents. ${ }^{35)}$ However, to obtain maximum efficacy and minimum toxicity, appropriate intestinal absorption of oral anti-cancer agents is required. ${ }^{36)}$ Therefore, to better understand the oral pharmacokinetic properties of the mercaptoacetamide-based HDAC inhibitor (W2), it is important to elucidate its intestinal absorption.

P-gp has been reported to alter the pharmacokinetics of numerous structurally and pharmacologically diverse drugs including anthracyclins, vinca alkaloids, podophyllotoxins and taxanes. ${ }^{28,29)}$ The present study provides a line of evidence indicating an important role for the transport proteins, and in particular P-gp, in the disposition of the mercaptoacetamide-based HDAC inhibitor. According to the data (Fig. 2), W2 exhibited asymmetric transport as indicated by 1.85 fold higher excretive $\left(P_{\mathrm{app}}=24.7 \pm 0.12 \times 10^{-6} \mathrm{~cm} / \mathrm{s}\right)$ than absorptive $\left(P_{\text {app }}=13.3 \pm 0.2 \times 10^{-6} \mathrm{~cm} / \mathrm{s}\right)$ flux. However, the presence of the P-gp inhibitor $(100 \mu \mathrm{M}$ verapamil) reduced markedly the secretory permeation $\left(P_{\text {app }}=12.7 \pm 0.22 \times 10^{-6}\right.$ $\mathrm{cm} / \mathrm{s}$ ) of W2 and increased significantly the absorptive transport $\left(P_{\text {app }}=17.3 \pm 0.12 \times 10^{-6} \mathrm{~cm} / \mathrm{s}\right)$ across the Caco-2 cell monolayer (Fig. 3). Further confirmation of the results was obtained by performing inhibition studies with cyclosporin A. This P-gp inhibitor significantly inhibited the polarized efflux of $\mathrm{W} 2$, i.e. the efflux ratio $P_{\text {app }} \mathrm{BL}$ to $\mathrm{AP} / P_{\text {app }}$ AP to BL decreased from 1.85 to 1.03 (Table 1). These results imply that P-gp might limit the oral bioavailability of W2 by transporting absorbed drug back into the lumen. Recent evidence indicates that in the intestine, P-gp inhibition ${ }^{30)}$ by coadministered compounds can increase the absorption of its substrate drugs and several clinically important interactions of this type have been documented..$^{37,38)}$

Clearly, to modulate resistance to cancer chemotherapy, a more comprehensive understanding of the interactions between efflux transporters and chemotherapeutic agents is required. The findings of our study revealed that the polarized transport of W2 was competitively inhibited by quinidne (Fig. 5), a mixed inhibitor of P-gp and MRP, suggesting involvement of multiple carriers in the efflux transport of W2. MRP is another protein associated with drug resistance, 
which could be another possible efflux protein decreasing absorption at the intestinal level. ${ }^{39)}$ The overlapping phenotypes mediated by P-gp and MRP1 suggests the possibility of W2 being an MRP1 substrate. ${ }^{40)}$ As shown by the apparent permeability coefficient values (Table 1), marked differences were observed between the secretion of W2 alone and in the presence of the MRP inhibitors. Indomethacin and NBI lowered the efflux ratio of $\mathrm{W} 2$ to 0.77 and 0.93 (Table 1), respectively, indicating the involvement of MRP1. Employing the Caco-2 cell line as a model of the intestinal mucosa, this is the first study that provides insight into the role and importance of the transporters in the disposition of the mercaptoacetamide-based HDAC inhibitor. However, due to the complex transport system, future studies using P-gp or MRP overexpressing cells should elucidate the individual role of each transporter in this process.

In summary, our findings provide initial evidence that the absorption and secretion of $\mathrm{W} 2$ are mediated by carrier mediated transport systems, including P-gp and MRP1. Therefore, the absorption of $\mathrm{W} 2$ could be enhanced by administered together with P-gp/MRP inhibitors. Further studies are required to elucidate other transport mechanisms involved in W2 transport as well as to explore the mechanism for the pharmacokinetic W2-drug interaction and ultimately, develop clinical strategies to overcome resistance.

Acknowledgements We thank Gene therapy pharmaceuticals for providing the compounds. This work was supported by the Grant, P02 CA74175 (to A.D. and M.J.) from the National Cancer Institute.

\section{REFERENCES}

1) Acharya M. R., Sparreboom A., Venitz J., Figg W. D., Mol. Pharm., 68, 917-932 (2005).

2) Karagiannis T. C., El-Osta A., Cell Cycle, 5, 288-295 (2006)

3) Minucci S., Pelicci P. G., Nat. Rev. Cancer, 6, 38-51 (2006).

4) Munster P. N., Troso-Sandoval T., Rosen N., Rifkind R., Marks P. A., Richon V. M., Cancer Res., 61, 8492 -8497 (2001).

5) Ryan Q. C., Headlee D., Acharya M., Sparreboom A., Trepel J. B., Ye J., Figg W. D., Hwang K., Chung E. J., Murgo A., Melillo G., Elsayed Y., Monga M., Kalnitskiy M., Zwiebel J., Sausville E. A., J. Clin. Oncol., 23, 3912-3922 (2005).

6) Carducci M. A., Gilbert J., Bowling M. K., Noe D., Eisenberger M. A., Sinibaldi V., Zabelina Y., Chen T., Grochow L. B., Donehower R. C., Clin. Cancer Res., 7, 3047-3055 (2001).

7) Byrd J. C., Marcucci G., Parthun M. R., Xiao J. J., Klisovic R. B., Moran M., Lin T. S., Liu S., Sklenar A. R., Davis M. E., Lucas D. M., Fischer B., Shank R., Tejaswi S. L., Binkley P., Wright J., Chan K. K., Grever M. R., Blood, 105, 959-967 (2005).

8) Takano M., Yumoto R., Murakami T., Pharmacol. Ther, 109, 137161 (2006).

9) Prime-Chapman H. M., Fearn R. A., Cooper A. E., Moore V., Hirst B. H., J. Pharmacol. Exp. Ther, 311, 476-484 (2004).
10) Artursson P., Palm K., Luthman K., Adv. Drug Deliv. Rev., 46, 27-43 (2001).

11) Brunet J. L., Maresca M., Fantini J., Belzunces L. P., Toxicol. Appl. Pharmacol., 194, 1-9 (2004).

12) Zhou S. F., Li Y., Kestell P., Schafer E., Chan E., Paxton J. W., Eur. J. Drug Metab. Pharmacokinet., 30, 49-61 (2005).

13) Hidalgo I. J., Raub T. J., Borchardt R. T., Gastroenterology, 96, 736749 (1989).

14) Delie F., Rubas W., Crit. Rev. Ther. Drug Carrier Syst., 14, 221-286 (1997).

15) Maeng H. J., Yoo H. J., Kim I. W., Song I. S., Chung S. J., Shim C. K., J. Pharm. Sci., 91, 2614-2621 (2002).

16) Hunter J., Jepson M. A., Tsuruo T., Simmons N. L., Hirst B. H., J. Biol. Chem., 268, 14991-14997 (1993).

17) Anderle P., Niederer E., Rubas W., Hilgendorf C., Spahn Langguth H., Wunderli Allenspach H., Merkle H. P., Langguth P., J. Pharm. Sci., 87, 757-762 (1998).

18) Chen B., Petukhov P. A., Jung M., Velena A., Eliseeva E., Dritschilo A., Kozikowski A. P., Bioorg. Med. Chem. Lett., 15, 1389-1392 (2005).

19) Konsoula R., Jung M., Int. J. Pharm., 361, 19-25 (2008).

20) Leslie E. M., Deeley R. G., Cole S. P. C., Toxicol. Appl. Pharmacol., 204, 216-237 (2005).

21) Sandstrom R., Karlsson A., Lennernas H., J. Pharm. Pharmacol., 50, $729-735$ (1988).

22) Cao J., Murase O., Schowen R. L., Aube J., Borchardt R. T., Pharm. Res., 18, 171-176 (2001).

23) Maguire A. R., Plunkett S. J., Papot S., Clynes M., O’Connor R., Touhey S., Bioorg. Med. Chem., 9, 745-762 (2001).

24) Rosenbaum C., Röhrs S., Müller O., Waldmann H., J. Med. Chem., 48, 1179-1187 (2005).

25) Konsoula R., Barile F., Toxicology in Vitro, 19, 675-684 (2005).

26) Artursson P., Karlson J., Biochem. Biophys. Res. Commun., 175, 880 885 (1991).

27) Meaney C., O’Driscoll C., Eur. J. Pharm. Sci., 8, 167-175 (1999).

28) Polli J. W., Wring S. A., Humphreys J. E., Huang L., Morgan J. B., Webster L. O., Serabjit-Singh C. S., J. Pharmacol. Exp. Ther., 299, $620-628$ (2001).

29) Benet L., Cummins C., Wu C., Curr. Drug Metab., 4, 393-398 (2003).

30) Matheny C., Lamb M., Brouwer K., Pollak G., Pharmacotherapy, 21, $778-796$ (2001).

31) Perloff M. D., Stormer E., von Moltke L. L., Greenblatt D. J., Pharm. Res., 20, 1177-1183 (2003).

32) Carrero J. C., Lugo H., Pérez D. G., Ortiz-Martínez C., Laclette J. P., Int. J. Pharm., 34, 1091-1097 (2004).

33) Hamilton K. O., Topp E., Makagiansar I., Siahaan T., Yazdanian M., Audus K. L., J. Pharmacol. Exper. Ther, 298, 1199-1205 (2001).

34) Suzuki T., Matsura A., Kouketsu A., Nakagawa H., Miyata N., Bioorg. Med. Chem. Lett., 15, 331-335 (2005).

35) DeMario M. D., Ratain M. J., J. Clin. Oncol., 16, 2557-2567 (1998).

36) Terwogt J. M. M., Schellens J. H. M., Huinink W. W. T., Beijnen J. H., Cancer Treat. Rev., 25, 83-101 (1999).

37) Adachi Y., Suzuki H., Sugiyama Y., Pharm. Res., 18, 1660-1668 (2001).

38) Aszalos A., Arch. Pharm. Res., 27, 127-135 (2004).

39) Kruh G. D., Zeng H., Rea P. A., Liu G., Chen Z. S., Lee K., J. Bioenerg. Biomembr., 33, 493-501 (2001).

40) van Zuylen L., Nooter K., Sparreboom A., Verweij J., Investig. New Drugs, 18, 205-220, 2000. 